\title{
A Study on Performance Evaluation of Public Sector Enterprise Textile Companies Using Shannon DEA Approach
}

\author{
Subir Kumar $\operatorname{Sen}^{1} \&$ Sudipta Kayal ${ }^{2}$ \\ ${ }^{1}$ Assistant Professor, Department of Commerce, Tripura University, Suryamaninagar, \\ Agartala-799022, Tripura, India. Email: subirkumarsen@gmail.com \\ ${ }^{2}$ Assistant Professor, Department of Economics, Savitri Girls' College, Kolkata-700007.
}

\begin{abstract}
:
This paper examines the combined efficiency of the Public Sector Enterprise Textile Firms using Shannon entropy measures. The efficiency scores of public sector enterprise Textile Firms under cost, revenue and profit models are combined to obtain a comprehensive performance measure. This paper finds that the profit model has a larger value of discriminatory ability and weight as compared to cost and revenue models.
\end{abstract}

Keywords: Shannon's entropy, cost efficiency, revenue efficiency, profit efficiency, ranking, Textile Companies.

JEL Codes: C14, D61

\subsection{Context of the Study:}

The Indian textile industry has been considered as one of the most important sector for the rapid growth of the Indian economy in terms of its contribution to both the central and state exchequers in India. After 1991, the Government of India initiated the deregulation of various sectors of Indian economy. Being the vital part of the economy, the Indian Textile sector policies have also gone for structural changes as per new economic situation and requirements to enhance the growth of this sector of the economy. To cope up with such challenges ahead, the PSE owned firms, in general, and Textile firms working as PSE should exhibit its efficiency against the bench mark standard.

In the existing literature on efficiency of firms, there exists number of approaches how to define efficiency. Farrell (1957) defined the efficiency of a firm in terms of two components: technical efficiency and allocate efficiency. Technical efficiency means the ability of a firm to obtain maximal output from a given set of inputs. On the other hand, allocative efficiency measures the ability of a firm to use the inputs in optimal proportions, given their prices and the available production technology. Further, these two types of efficiency are combined and termed as overall economic efficiency, which can be examined from the perspective of either input or output based models. After which, the concepts of overall cost efficiency (input perspective) or overall revenue efficiency (output perspective) comes into the picture. The conventional firms' theories assume that firms earn profits by purchasing inputs directly from the market and convert them into output subject to the available technology, based on its comparative advantage at gathering information and underwriting risk (Santos, 2000). Traditionally, the cost efficiency is assumed to measure how close a firms' cost is to what a best-practice firms' cost would be for producing the same amount of output in the same period under the given conditions. Revenue efficiency indicates how well a company is predicted to perform in terms of revenue relative to other firms in the same period for producing the same amount of outputs. According to Bader (2008), profit efficiency indicates how well a company is expected to perform in term of profit as compared to other firms in the same period for 
producing the same amount of outputs. Most studies have focused on the input side, estimating cost efficiency of firms (Berger, Hunter and Timme (1993); Resti (1997)). A few studies have examined the output side evaluating revenue and profit efficiency (Maudos et al ,2002; Bader et al, 2008)). Since both the approaches are relevant when evaluating efficiency of firms, this paper deals with the Data Envelopment Analysis (DEA) method and describes its application in measuring cost, revenue and profit efficiency.

Bader, Mohamad \& Hassan (2008) in their paper, made an attempt to measure and compare the cost, revenue and profit efficiency of 43 Islamic and 37 conventional firms over the period 1990-2005 in 21 countries using DEA. It assesses the average and overtime efficiency of those firms based on their size, age, and region using static and dynamic panels. This paper assumes that both conventional and Islamic firms are cost minimisers, and revenue and profit maximisers. This paper investigates the differences in mean and overtime cost, revenue, and profit efficiency scores of conventional versus Islamic firms. This study revealed that there are no significant differences between the overall efficiency results of conventional versus Islamic firms. The results in this paper indicated that there is a slack in the usage of resources across all firms, as measured by the efficiency results of the average firms. Therefore, there is substantial room for more cost, revenue, and profit efficiency in both companying systems. Menon \& Tahir (2012) measured and evaluated the relative efficiency of 49 firms in Pakistan using DEA. The DEA results under the CRS technology assumption showed that 8 firms are considered technically efficient, while the average technical overall technical efficiency (OTE) varies from 0.83 to 0.86 . When the aggregate efficiency is decomposed into pure technical efficiency and scale efficiency using VRS production function, it is found that the source of inefficiency is pure technical inefficiency rather than scale inefficiency. Most of the firms found operating under increasing returns to scale. This indicates that managers' capabilities to utilize a company's given resources still need to be enhanced. In addition, the results indicate that on average, 13 out of 49 firms are in Quadrant 1 (superstar) characterised by high efficiency and high profitability while 20 firms are in Quadrant IV (problem child), characterised by low efficiency and low profitability. Jayaraman \& Srinivasan (2014) have made an attempt to evaluate the performance of the firms in India using cost, revenue and profit models of DEA and comes out with a comprehensive efficiency index for firms, by combing the efficiency scores of various DEA models, using the Shannon entropy. In general, the firms included in this study are sound in terms of total assets, manpower, branch network etc., and they have been ranked based on their performance, which depends on optimal utilization of select variables. In order to measure the degree of agreement between rankings of firms based on three different models, namely cost, revenue and profit model, Kendall's coefficient of concordance have been used. The study observes that Shannon-DEA approach provides a comprehensive efficiency index for firms and a reasonable way of ranking. As to the technique employed, although most of the studies analyze cost efficiency with parametric techniques and with non-parametric techniques, only one study (Fare et al, 1997b) analyses standard profit efficiency by non-parametric methods, but without comparing it with cost efficiency, and there is no study in the literature that calculates alternative profit efficiency by non-parametric methods. Recently Sen and Das (2016) has applied the Shannon entropy approach to find the combined ranking for the public sector enterprise steel firms in India. In this context, the aim of the study is to analyze the overall efficiency of the public sector enterprise Textile firms in a decade characterized by continual changes. In order to enrich the analysis, the study shall compare cost efficiency, revenue efficiency and profit efficiency using a non-parametric approach. For this purpose this study uses the innovative methodology of a non-parametric technique for estimating alternative profit efficiency both of which does allow the existence of market power.

To the best of our knowledge, there is no study is available till date, at least in India, investigating firms from public sector owned textile industry using cost, revenue and profit efficiency measures altogether. Hope, this study shall attempt to fill up that caveat in the existing literature. Therefore, this study shall take into account all of cost, revenue and profit efficiency, not one or some of these efficiency measures.

\subsection{Objective of the Study}

The area of research which is proposed here is basically an attempt to rank comprehensively the performance of the selected public sector owned textile companies on the basis of cost efficiency, revenue efficiency and profit efficiency using Shannon entropy approach. The specific objectives of this study are three fold. These are as following: 
1. To investigate the nature and trend of efficiency of public sector owned companies in terms of cost, revenue and profit.

2. To examine the relative weight of each of the aspects mentioned above..

3. To determine the overall ranking of the companies using Shannon entropy approach.

\subsection{Source of Data}

This study is basically an empirical research and the data has been collected from Secondary sources. The study focused on comparing performance of PSE Textile industry in India. Thus, the five Indian PSE Textile companies which cover major share of the industry were selected for analysis. The Reference study period was 04 years FY 2010 to FY 2013 i.e. 2010-2013.

The sources of data included Secondary data from various sources. The Annual reports, websites, Research reports, presentations made by company officials of target companies were used for the analysis of the companies. The reports of Ministries and various committees were also used to get the macro data of the Indian PSE Textile Industry

\subsection{Methodology}

Methodological aspects are presented in the following subsections.

\subsubsection{Cost Efficiency DEA Model:}

To illustrate the non-parametric methodology for calculating cost efficiency, let us suppose that there exists $\mathrm{N}$ firms $(\mathrm{i}=1, \ldots, \mathrm{N})$ that produce a vector of $\mathrm{q}$ outputs $\mathrm{yi}=(\mathrm{yi} 1, \ldots, \mathrm{yiq})$ and that they sell at prices

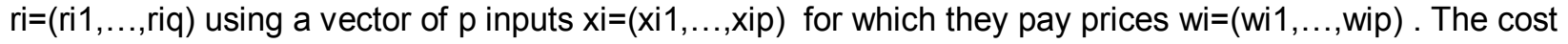
efficiency for the case of firm $\mathrm{j}$ can be calculated by solving the following linear programming problem:

$$
\begin{aligned}
\text { Min } & \sum_{p} w_{j p} x_{j p} \\
\text { s.t. } & \sum_{i} \lambda_{i} y_{i q} \geq y_{j q} \\
& \sum_{i} \lambda_{i} x_{i p} \leq x_{j p} \\
& \sum_{i} \lambda_{i}=1 \text {; for all } \mathrm{i}=1,2, \ldots . . \mathrm{m}
\end{aligned}
$$

The solution to which, $x^{*} j=\left(x^{*} j 1, \ldots, x^{*} j p\right)$ corresponds to the input demand vector which minimizes the costs with the given prices of inputs. Accordingly, the minimum cost is

$$
C_{j}^{*}=\sum w_{p j} \cdot x_{p j}^{*}
$$

Hence, the cost efficiency for firm $\mathrm{j}$ is

$$
C E_{j}=\frac{\sum_{p} w_{j p} x_{j p}^{*}}{\sum_{p} w_{j p} x_{j p}}
$$

where $\mathrm{CE}_{\mathrm{j}} \leq 1$. 


\subsubsection{Revenue Efficiency DEA Model:}

Following Zhu (2002) the revenue efficiency model may be presented as:

$\operatorname{Max} \sum_{q} r_{j} y_{j q}$

s.t. $\sum_{i} \lambda_{i} y_{i q} \geq y_{j q}$

$\sum_{i} \lambda_{i} x_{i p} \leq x_{j p}$

$\sum_{i} \lambda_{i}=1 ;$ for all $\mathrm{i}=1,2, \ldots . . \mathrm{N}$

By similar logic, revenue efficiency of any firm can be calculated as:

$R E_{j}=\frac{\sum_{q} r_{j} y_{j q}}{\sum_{q} r_{j} y^{*}{ }_{j q}}$

\subsubsection{Profit Efficiency DEA Model:}

Following Zhu (2002), Fare and Grosskopf (1997) and Fare et al. (2004), the profit efficiency model may be represented as:

$\operatorname{Max}\left(\sum_{q} r_{j} y_{j q}-\sum_{p} w_{j p} x_{j p}\right)$

s.t. $\sum_{i} \lambda_{i} y_{i q} \geq y_{j q}$

$\sum_{i} \lambda_{i} x_{i p} \leq x_{j p}$

$\sum_{i} \lambda_{i}=1 ;$ for all $\mathrm{i}=1,2, \ldots . . \mathrm{N}$

Hence, the profit efficiency of any firm is

$P E_{j}=\frac{\sum_{q} r_{j} y_{j q}-\sum_{p} w_{j p} x_{j p}}{\sum_{q} r_{j} y_{j q}^{*}-\sum_{p} w_{j p} x^{*}{ }_{j p}}$

where $P E_{j}$ represents the ratio between the observed profits $\left({ }_{\mathrm{j}}\right)$ and the maximum profits $\left(\mathrm{SP}_{\mathrm{j}}{ }_{\mathrm{j}}\right)$ associated with the production of the output vector $y^{*} j$ and with demand for inputs $x^{*} j$ which maximize profits for firm $\mathrm{j}$. It can be inferred from model 6 that if a DMU has a loss, the efficiency score will be negative. Therefore, it can be concluded that the efficiency score might be between 1 and $-\infty$.

\subsubsection{Shannon Entropy Measures}

DEA has several advantages over other parametric methods. First, it does not assume any explicit functional form for production function, like parametric methods. On the other hand, DEA has a few limitations like high sensitivity to data error and outliers, inability to capture random effects etc. Another limitation of DEA may be ranking of DMUs based on efficiency scores obtained from various DEA models. 
Since efficiency scores obtained from different DEA models may not be same, identifying a suitable model to rank the DMUs is a difficult task. Further, since each model and its viewpoint have some valuable advantage over the other, one may not like to ignore the efficiency scores obtained from various models while ranking the DMUs. For this, Soleimani-damaneh and Zarepisheh (2009) proposed combining of efficiency scores of various DEA models using Shannon's entropy method to provide a more balance ranking of DMU. Bian and Yang (2010) also used Shannon-DEA procedure to establish a comprehensive efficiency measure for appraising DMUs resource and environment efficiencies. In Indian context, Sen and Das $(2015,2016)$ have applied this methodology to find the comprehensive ranking arising out of different efficiency measures.

Suppose, $E_{\mathrm{ij}}$ measures the efficiency score of $\mathrm{i}^{\text {th }}$ firm under $\mathrm{j}^{\text {th }}$ DEA model then

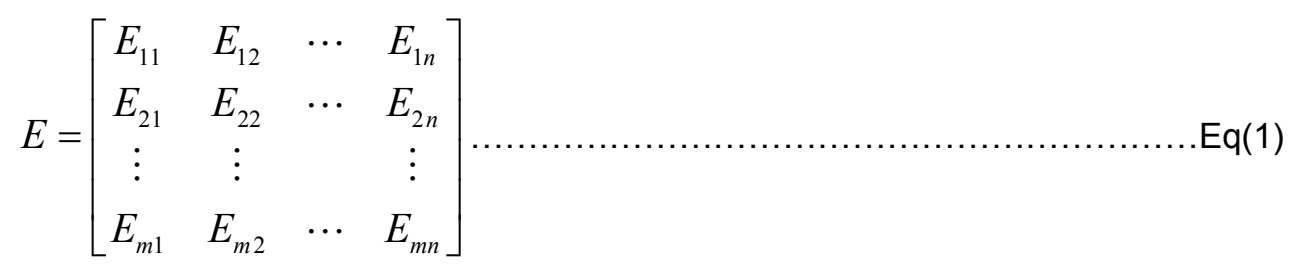

Normalize the Efficiency matrix as following:

$$
\bar{E}_{i j}=E_{i j} / \sum_{i=1}^{m} E_{i j} \text { for all } \mathrm{i}=1,2, \ldots . \mathrm{m} \& \mathrm{j}=1,2, \ldots \mathrm{n}
$$

Further, the Shannon entropy for each model is calculated using:

$$
e_{j}=-e_{0} \sum_{i=1}^{m} \bar{E}_{i j} \ln \bar{E}_{i j} \text { for all } \mathrm{j}=1,2, \ldots \mathrm{n}
$$

$$
\mathrm{e}_{0}=-(\ln n)^{-1}
$$

For each model,

$$
\begin{aligned}
& \mathrm{d}_{j}=1-e_{j} \\
& w_{j}=d_{j} / \sum_{j=1}^{n} d_{j} \\
& \beta_{i}=\sum_{j=1}^{n} w_{j} E_{i j} \text { for all } \mathrm{i}=1,2, \ldots, \mathrm{m}
\end{aligned}
$$

\subsection{Selection of Variables}

The sample consists of 5 Textile companies working as PSE in India. In order to increase reliability and comparability, all of the companies have been selected among a same industry namely PSE Textile industry for a four-year period (2009 to 2012). Considering the objectives of this research, that are measuring cost, revenue and profit efficiency and investigating the combined ranking of companies in different period as DMUs, the research variables consists of input and output variables of DMUs aiming at the measurement of cost, revenue and profit efficiency that are summarized in Table 1.

\subsection{Organization the of Study}

The remaining Study is organized as follows. Apart from the introductory section, Section 2 presents the profile of the selected public sector owned textile firms and the results are presented and discussed in Section 3. Finally, Section 4 concludes the study. 


\subsection{Profile of the Selected Public Sector Owned Textile Companies}

As on 31.03.2014, there were 4 Central Public Sector Enterprises in the Textile group. The names of these enterprises along with their year of incorporation in chronological order are given below:

Table 1: List of Central Public Sector Enterprises in the Textile Group

\begin{tabular}{|c|l|c|}
\hline SI No & Enterprises & Year of Incorporation \\
\hline 1 & Birds jute \& export Ltd & 1904 \\
\hline 2 & British India & 1920 \\
\hline 3 & National jute & 1980 \\
\hline 4 & National Textile & 1968 \\
\hline
\end{tabular}

Source: public Sector Enterprises Survey, Gol, New Delhi, 2012

The enterprises falling in this group are mainly engaged in manufacturing, repairing overhauling and selling of Textiles viz., aircrafts, helicopters, ships, tugs, barges, trawlers, assault boats, floating docks, dredgers, heavy moving equipments, rail coaches, road rollers, scooters, trucks etc.

\section{Birds Jute \& Export Limited (BJEL)}

Birds Jute \& Export Limited (BJEL) was incorporated on 02.07.1904 under the name and style of the Lansdowne Jute Company Limited with the objective of taking over as a going concern, the business of the manufacturing jute goods at Dakhindari from the Arathoon Jute Mills Limited. The name of the company has been changed to M/s Birds Jute \& Export Limited with effect from the 15th December, 1971 and was decided to be run as a processing factory for Bleaching, Dyeing, Cotton and Blended Fabrics. It became a $100 \%$ subsidiary of National Jute Manufactures Corp. Ltd. (NJMC) on 20.11.1986 after remaining closed for around 7 years due to financial stringency. BJEL is an un-categorized / BIFR / BRPSE / Taken over sick CPSE in Textile sector under the administrative control of M/o Textile. Its Registered and Corporate offices are at Kolkata, West Bengal.

British India Corp. Ltd. (BIC)

British India Corp. Ltd. (BIC) was incorporated in the year 1920 in the private sector and was nationalized in 1981 under B.I.C. Ltd. (Acquisition of Shares) Act with the objective to take over the controlling shares from private hands. BIC is a Schedule-'B'/ BIFR / BRPSE referred / taken over CPSE in textile sector under the administrative control of M/o Textile with $99.75 \%$ shareholding by the Government of India. Its Registered and Corporate offices are at Kanpur, Uttar Pradesh.

\section{National Jute Manufactures Corporation Ltd}

National Jute Manufactures Corporation Ltd. (NJMC) was incorporated on 3.6.1980 with the objective to take over six jute mills, the management of which was earlier taken over by the Government of India under the Industries (Development and Regulation) Act, 1951. NJMC is a Schedule 'B' / sick BIFR referred CPSE in Textile sector under the administrative control of $\mathrm{M} / \mathrm{o}$ Textile with $100 \%$ shareholding by the Government of India. Its Registered and Corporate offices are at Kolkata, West Bengal.

\section{National Textile Corporation Ltd. (NTC)}

National Textile Corporation Ltd. (NTC) was established in 1968 with the main objective of managing the affairs of 124 sick textile mills taken over by the Government of India in three series of Nationalization Acts viz., The Sick Textile Undertakings (Nationalization) Act, 1974, The Swadeshi Cotton Mills Company Limited (Acquisition and Transfer of Undertakings) Act, 1986 and The Textile Undertakings (Nationalization) Act, 1995. NTC is a Schedule-'A' BIFR / BRPSE referred CPSE in Textile sector under the administrative control of M/o Textile with $100 \%$ shareholding by the Government of India. Its Registered and Corporate offices are at New Delhi.

\section{Results \& Discussion}

\subsection{Descriptive Statistics:}


The following table presents the summary statistics (mean and standard deviation) of the input-output variables used in this study.

Table 1: Descriptive Statistics for the Selected Indicators for F.Y 2010-2013

\begin{tabular}{|c|c|c|c|c|c|}
\hline Symbol & Definition & 2013-14 & 2012-13 & 2011-12 & 2010-11 \\
\hline \multirow[t]{2}{*}{$X 1$} & No of Employee & 2538 & 2588 & 2698 & 2930 \\
\hline & & $(3966)$ & $(3677)$ & (3972) & $(4310)$ \\
\hline \multirow[t]{2}{*}{$X 2$} & $\begin{array}{l}\text { Physical capital = book value of } \\
\text { fixed assets }\end{array}$ & 37134 & 37134 & 37134 & 37134 \\
\hline & & $(67590)$ & $(57742)$ & $(57839)$ & $(42069)$ \\
\hline \multirow[t]{2}{*}{$Y$} & Cost of goods sold (COGS) & 29826 & 25032 & 22916 & 16396 \\
\hline & & $(51407)$ & $(43730)$ & $(40834)$ & $(29670)$ \\
\hline \multirow[t]{2}{*}{$F$} & Personal Expenses & 8406 & 7206 & 7776 & 6783 \\
\hline & & $(12385)$ & $(10562)$ & $(12274)$ & $(10853)$ \\
\hline \multirow[t]{2}{*}{$W 1$} & $\begin{array}{l}\text { Price of labour }=\text { personnel } \\
\text { expenses } / \text { x } 1\end{array}$ & 547 & 569 & 5 & 2 \\
\hline & & $(1091)$ & $(1133)$ & (3) & (2) \\
\hline \multirow[t]{2}{*}{$v i-f$} & $\begin{array}{l}\text { Total Expenditure-Salary \& } \\
\text { Wages }\end{array}$ & 22557 & 19534 & 19541 & 10998 \\
\hline & & $(40878)$ & $(35616)$ & $(36830)$ & $(20959)$ \\
\hline \multirow[t]{2}{*}{$W 2$} & $\begin{array}{l}\text { [Total Expenditure-Salary \& } \\
\text { Wages]/X2 }\end{array}$ & 1 & 0 & 0 & 0 \\
\hline & & $(0)$ & $(0)$ & $(0)$ & $(0)$ \\
\hline \multirow[t]{2}{*}{$r$} & $\begin{array}{l}\text { Price of COGS = operating } \\
\text { revenues / Y }\end{array}$ & 1 & 0 & 0 & 1 \\
\hline & & $(0)$ & $(0)$ & $(0)$ & $(0)$ \\
\hline$R$ & Revenues & 26935 & 17732 & 16542 & 12505 \\
\hline
\end{tabular}

Source: Author's Calculation

\subsection{DEA Results}

Using the cost, revenue and profit models of DEA discussed in Section 1, the year-wise efficiency scores for 4 companies is calculated under each model. The average efficiency score for each firm under each model is obtained by averaging the year-wise efficiency score. The average efficiency scores of firms under each model are presented in the following table

Table 2:-Average Efficiency scores of Textile industry under DEA Models

\begin{tabular}{|l|r|r|r|}
\hline DMU & COST & REVENUE & \multicolumn{2}{|l|}{ PROFIT } \\
\hline BIRDS JUTE & 0.254 & 0.618 & 0.1865 \\
\hline BRITISHINDIA & 0.180 & 0.814 & 0.8565 \\
\hline NATIONAL JUTE & 0.492 & 0.5765 & 0.0715 \\
\hline NATIONAL TEXT. & 0.115 & 0.86475 & 0.218 \\
\hline
\end{tabular}


Source: Author's calculation

It is evident from the above table that averages of cost, revenue and profit efficiency of firms separately are in the range of $(0.115,0.492),(0.5765,0.86475)$ and $(0.0715,0.8565)$ respectively. From the above table, it is found that the variation in profit can best be explained in terms of the variation in cost for a given level of revenue as compared to the variation in profit due to variation in revenue for a given level of cost. Further, based on the average efficiency score so obtained for the selected firms, they are ranked separately using cost, revenue and profit efficiency score.

Table 3:-Ranking Based on Average Efficiency Scores

\begin{tabular}{|l|r|r|r|}
\hline DMU & Cost & Revenue & Profit \\
\hline BIRDS JUTE & 4 & 3 & 3 \\
\hline BRITISHINDIA & 2 & 2 & 2 \\
\hline NATIONAL JUTE & 3 & 1 & 1 \\
\hline NATIONAL TEXT. & 1 & 4 & 4 \\
\hline
\end{tabular}

Source: Author's Calculation

it can be observed that ranking of firms based on three models exhibits a similarity in ranking. Kendall's coefficient of concordance ( $\mathrm{W}=0.213$, Chi- Square $=2.55$ with $p$-vale $=0.466>0,05)$ also confirms that there is hardly an agreement in the ranking obtained from the three models.

Since each efficiency model and its viewpoints has some valuable advantage over other, ranking of firms by combining the efficiency scores from three models may be a reasonable way of ranking the firms. The Shannon's entropy discussed in Section 1 provides a methodology to combine the efficiency scores as well as a reasonable way of ranking the firms.

In Shannon entropy method, first, the efficiency scores are normalized to obtain the discriminatory power of each model i.e. the degree of diversification. Using the degree of diversification, the degree of importance is calculated for each model and finally comprehensive efficiency index i.e. Shannon index for each firm is obtained a by multiplying the efficiency scores of various models with corresponding degree of importance. Table 4 presents the importance degree of various models.

Table 4: Entropy, Degree of Diversification and Importance

\begin{tabular}{|l|r|l|l|}
\hline MODEL & COST & REVENUE & PROFIT \\
\hline ej & 0.23 & 0.37 & 0.37 \\
\hline dj=1-ej & 0.77 & 0.63 & 0.63 \\
\hline wj & 0.38 & 0.31 & 0.31 \\
\hline
\end{tabular}

Source: Author's calculation

As mentioned earlier, the degree of diversification indicates the discrimination power of a given DEA model. Larger value of dj indicates the more discriminatory power of a DEA model. It can be observed from Table 4 that cost model has a larger value of discriminatory power $(0.766)$ when compared with other two models namely revenue and profit models. Lower value of discriminatory power (dj) for revenue and profit model indicates that the model has least / no discriminatory ability to differentiate the firms which is due to efficiency scores of firms being approximately equal under this model. The discriminatory power of each model determines the degree of importance or weights for each model (wj) and it can be seen from Table 5 that cost model has higher degree of importance $(0.378085)$ followed by revenue and 
profit models with degree of importance both are 0.310958 . The comprehensive Shannon index for each firm based on three models and their corresponding ranks based on the index is presented in Table 5 .

Table 5: Shannon Index and Ranking

\begin{tabular}{|l|r|r|}
\hline DMU & Shannon Index & Shannon Rank \\
\hline BIRDS JUTE & 0.61 & 1 \\
\hline BRITISHINDIA & 0.56 & 2 \\
\hline NATIONAL JUTE & 0.44 & 3 \\
\hline NATIONAL TEXT. & 0.10 & 4 \\
\hline
\end{tabular}

Source: Author's Calculation

\section{Conclusions}

This study has attempted to rank the performance of the selected firms on the basis of cost efficiency, revenue efficiency and profit efficiency using Shannon entropy approach. Using the Shannon entropy method, the efficiency scores of PSE owned textile firms under cost, revenue and profit models are combined to obtain an aggregate performance measure for each firm. Results of degree of diversification and degree of importance associated with each model suggest that profit model has a larger value of discriminatory ability and weight compared to cost and revenue models. Firms which are close to profit and cost efficient frontiers are ranked better under Shannon index compared to those which are away from the efficient frontiers. In general, firms which are closed to efficient frontier are ranked better compared to those which are away from the efficient frontier under Shannon index. In conclusion, it may be pointed out that Shannon-DEA approach provides a comprehensive efficiency index for firms as well as a reasonable way of ranking the firms.

\section{References}

Afriat, S. (1972). Efficiency Estimation of Production Function. International Economic Revenue , 13, 568-598.

Anderson, R., Lewis, D., \& Zumpano, L. (2000). Residential Real Estate Brokerage Efficiency from a Cost and Profit Perspective. J. Real Estate Financ. Econ. , 20 (3), 295-310.

Bader, M. K., Mohamad, S., Ariff, M., \& Hassan, T. (2008). Cost, Revenue, and Profit Efficiency of Islamic Versus Conventional Firms: International Evidence Using Data Envelopment Analysis. Islamic Economic Studies , 15 (2).

Banihashem, S., Sanei, M., \& Manesh, Z. M. ( 2013). Cost, revenue and profit efficiency in supply chain. African Journal of Business Management , 7 (41), pp 4280-4287.

Firmer, R., \& Maindiratta, A. (1988). NonParametric Analysis of Technical and Allocative Efficiencies in Production. 1315-1332.

Bhatt, M. S., \& Bhat, S. A. (2013 ). Financial Performance and Efficiency of Cooperative Firms in Jammu \& Kashmir(India). Journal of Co-Operative Accounting and Reporting , 2 (1), pp 16-36.

Berger, A., \& Master, L. (1997). Inside the Black Box: What Explains Differences in the Efficiencies of Financial Institutions . J. Firming Financ, 895-947.

Charnes, A., Copper, W., \& Rhodes, E. (1978). Measuring the Efficiency of Decision Making Units . Eur. J. Oper , 429-444. 
Copper, W., Park, K., \& Yu, G. (2001). An Illustrative Application of Idea (Imprecise Data Envelopment Analysis) to a Korean Mobile Telecommunication Company . 807-820.

Dalfard, V. M., Sohrabian, A., Najafabadi, A. M., \& Alvani, J. (2012). Performance Evaluation and Prioritization of Leasing Companies Using the Super Efficiency Data Envelopment Analysis Model. Acta Polytechnica Hungarica , 9 (3).

Devi, B. M., \& Sabarinathan, K. (2015). A Study on Financial Performance of Textile Industries in Tamilnadu with Reference to Select Textile Companies. International Journal of Research in Management \& Technology (IJRMT) , 5 (1).

Fare, F., Grosskopf, S., \& Weber, W. (2004). The Effect of Risk-based Capital Requirements on Profit Efficiency in Firming . Applied Economics, 36 (15), 1731-1743.

Fare, R., \& Grosskopf, S. (1995). Non-Parametric Tests of Regularty. Farrell Efficiency, And Goodness of Fit. , 415425.

Fare, R., \& Grosskopf, S. (1997). Profit Efficiency. Farrell Decomposition And the Mahler Inequality , $283-287$.

Fare, R., Grosskopf, S., \& Webe, W. (2004). The effect of risk- Based Capital Requirments of Profit Efficiency In Firming. APPI, 1731-1743.

Geetha, M. T., \& Ramasamy, S. (2014). A Study on the Financial Performance Efficiency of Selected Textile Industries in India. International Journal of Emerging Engineering Research and Technology , 2 (3), PP 106-111.

Goto, M., \& Tsutsui, M. (1998). Comparison of Productive and Cost Efficiencies Among Japanese and US Electric tilities . Omega: Int.J. Manag , 26 (2), 177-194.

Halkos, G., \& Salamouris, D. (2004). Efficiencies Measurement of the Greek Commercial Firms with the use of Financial Ratios:A Data Envolvement Analysis Approach. Manage Account. Res , 15, 201-224.

Hirad, A. (2014). Designation and Explanation of Performance Evaluation Model Metals Producers Companies in Iran Stock Exchange with an Approach to Data Envelopment Analysis. International Journal of Academic Research in Accounting, Finance and Management Sciences , 4 (4), pp. 44-59.

Huang, M. Y., \& Huang, S. Y. (2009). Productivity Evaluation of Taiwanese Semiconductor Companies Using a Three-stage Malmquist DEA Approach.

Ibrahim, B. M., \& Sasikala, P. (2014). Efficiency and Productivity Analysis of Puducherry Cooperative Firms by Using DEA APPROACH. International Journal of Scientific Research , 3 (5), pp 375-378.

Jayaraman, A., \& Srinivasan, M. (2009). Relative Efficiency of Scheduled Commercial Firms in India(2001-08). A DEA Approach. Prajnan , XXXVIII (2).

Kumar, S., \& Gulati, R. (2008). An Examination of Technical,Pure Technical, and Scale Efficiencies in Indian Public Sector Firms Using Data Envelopment Analysis. Eurasion Journal of Business and Economics , 1 (2), 33-69.

Maudos, J., \& Pastor J, M. (2003). Cost and Profit Efficiency in the Spanish Firming Sector(1985-96): A nonparametric Approach . Applied Financial Economics , 13 (1), 1-12.

Menon, M. A., \& Tahir, I. M. (2012). Company Operation Performance Using DEA and Performance Matrix: Evidence from Pakistan. International Journal of Business and Behavioral Sciences , 2 (2).

Maudos, J., Pastor, J., Pe'rez, F., \& Quesaba, J. (2002). Cost and Profit Efficiency in European Firms. J. Int. Financ. Mark. Inst. Money, 12, 33-58.

Mohamad, N. H., \& Said, F. (2012). Using Super-Efficient Dea Model to Evaluate the Business Performance in Malaysia. World Applied Sciences Journal , $17(9)$, pp 1167-1177.

Nikoomaram, H., Mohammadi, M., \& Mahmoodi, M. (2010). Efficiency Measurement of Enterprises Using the Financial Variables of Performance Assessment and Data Envelopment Analysis. Applied Mathematical Sciences , 4 (37), pp $1843-1854$

Ray, S., \& Das, A. (2010). Distribution of Cost and Profit Efficiency :Evidence from Indian Firming. European Journal of Operational Resarch , 201 (1), 297-307.

Sen, S. K., \& Das, J. (2015). Combined Ranking of Selected Public Sector Enterprise Transportation Equipment Companies: A Shannon-DEA Approach. Time's Journey , 4(1). 1-17

Sen, S. K., \& Das, J. (2016). A Study on Performance Evaluation of Public Sector Enterprise Steel Companies Using Shannon DEA Approach, 21, 116-131 
27 A Study on Performance Evaluation of Public Sector Enterprise Textile Companies Using Shannon DEA Approach

Sarangarajan, V., \& Tamilenthi, S. ( 2012). A Study on Cost Efficiency of Textile Industries in Tamilnadu Using an Application of DEA Analysis. International Journal of Recent Scientific Research , 3 (5), 413 - 416.

Sharath Kumar, K. M., Narahari, H. K., \& Rowley, J. (2012). Development of Multi-Stage Supplier Performance Evaluation using DEA and Econometrics. Research Journal of Management Sciences , 1(2), 8-14.

Soleimani-damaneh, M., \& Zarepisheh, M. (2009). Shannon's Entropy for Combining the Efficiency Results of Different DEA Models: Methods and Application. Expert Systems with Applications , 36, 5146-5150.

Tehrani, R., Mehragan, M. R., \& Golkani, M. R. (2012). A Model for Evaluating Financial Performance of Companies by Data Envelopment Analysis. International Business Research , 5 (8).

Zhu, J. (2002). Quantitative Models for Performance Evaluation and Benchmarking: Data Envelopement Analysis with Spreadsheed and DEA Excel Solver. Norwell ,MA:Kluwer Academic Publishers Group.

Zhu, J. (2009). Quantitative Models for Performence Evaluation and Benchmarking Data Envelopment Analysis with Spreadsheets . Springer Publisher, North Holand 